\title{
Ensino Superior: prática docente e teoria
}

\author{
Juliana Ferreira Dos Santos \\ Marcos Rogério Martins Costa \\ Patrícia Margarida Farias Coelho
}

\section{Resumo}

Neste artigo, o objetivo é analisar o tema do conceito de prática docente em paralelo com o de teoria crítica aplicada ao Ensino Superior Brasileiro, a partir de um estudo bibliográfico. Entende-se por prática docente uma prática social orientada por objetivos, finalidades e conhecimentos, inseridos no contexto de ensino e aprendizagem, conforme Veigas (1989). Como metodologia, utilizamos a revisão bibliográfica de autores especialistas na área, como Lima (2012), Demo (2001) e Cunha (2006). Como resultados deste estudo, compreendemos que a pesquisa científica corrobora a elaboração, dá apoio aos projetos de desenvolvimento à educação e oferece metodologia e fundamento epistemológicos à área. Por isso, é necessária e fundamental a relação entre prática docente e teoria, uma convocando e estimulando a outra.

Palavras-chave: Ensino superior; Teoria; Prática docente.

\section{College Education: teaching practice and theory}

\section{Abstract}

In this article, the objective is to analyze the theme of the concept of teaching practice in parallel with that of critical theory applied to Brazilian Higher Education, based on a bibliographic study. We understood by teaching practice a social practice oriented by objectives, aims and knowledge, inserted in the context of teaching and learning, according to Veigas (1989). As a methodology, we used the literature review of specialists in the area, such as Lima (2012), Demo (2001) and Cunha (2006). As results of this study, we understand that scientific research corroborates the elaboration, gives support to projects development to education and 
offers methodology and epistemologicalfoundation to the area. Therefore, it is necessary and fundamental the relationship between teaching practice and theory, one calling and stimulating the other.

Keywords: College education; Theory; Teaching practice.

\section{Enseñanza Superior: práctica docente y teoría}

\section{Resumen}

En este artículo, el objetivo es analizar el tema del concepto de práctica docente en paralelo con el de teoría crítica aplicada a la Enseñanza Superior Brasileña, a partir de un estudio bibliográfico. Entendemos por práctica docente como una práctica social orientada por objetivos, finalidades y conocimientos, insertados en el contexto de enseñanza y aprendizaje, conforme a Veigas (1989). Como metodología, utilizamos la lectura bibliográfica de autores especialistas en el área, como Lima (2012), Demo (2001) y Cunha (2006). Como resultados de este estudio, comprendemos que la investigación científica corrobora la elaboración, da apoyo a los proyectos de desarrollo a la educación y ofrece metodología y fundamentos epistemológicos al área. Por eso, es necesaria y fundamental la relación entre práctica docente y teoría, una convocando y estimulando la otra.

Palabras-clave: Enseñanza superior; la teoría; Práctica docente.

\section{Introdução}

O termo docência define um campo semântico mais abrangente do que o sentido do senso comum que é o de ministrar aulas. No caso do ensino superior, esse conceito ganha outros matizes de significação. Para Lima (2012, p. 141), há diferença entre docência universitária e ensino superior. O primeiro conceito destacado pela autora designa o nível em que ocorre a prática docente e as atividades desenvolvidas pelos professores regentes; já o segundo está relacionado intrinsecamente às instituições de ensino superior. Para além dessa diferença conceitual, a estudiosa, ainda, assevera que existem diversas conotações para o termo docência: trabalho docente, trabalho acadêmico, exercício profissional, prática docente, dentre outros.

Diante das demandas do dia-a-dia, o professor universitário precisa ser um profissional que necessita desenvolver ao mesmo 
tempo diversas e diferentes habilidades ao mesmo tempo. (BOTOMÉ, 1996). Por exemplo, o docente universitário deve ser competente como pesquisador em uma área do conhecimento, em relação ao ensino, precisa ser capaz de ensinar e formar profissionais. (LIMA, 2012, p. 146).

Conforme Dencker (2002 p. 69), um dos principais desafios dos professores universitários, é a falta de tempo e de recursos materiais para promover a sua reciclagem e atualização. Isso torna necessário o estabelecimento de políticas viabilizantes para adequada formação do docente na busca de um melhor índice da qualidade por parte das universidades Necessita-se, portanto, de uma reorganização da prática docente nas universidades brasileiras.

Um dos passos para se efetivar essa reorganização é a valorização do professor universitário no âmbito acadêmico. Embora essa condição possa variar em intensidade segundo a origem da área, ela se alicerça nas atividades de pesquisa, de ensino e de extensão. E entre essas demandas, o docente deve ser também valorizado em seu processo de orientação científica, uma vez que é essa parte de sua atuação docente que garante a renovação, formação e consolidação das áreas do conhecimento, conforme Cunha (2006 p.258).

O cenário do ensino superior no Brasil tem propiciado a desvalorização da função docente e o não cumprimento de um conjunto de direitos profissionais, causando instabilidade e fragilidade da coletividade (LIMA, 2012), em contrapartida Dencker (2002, p. 35), salienta que o ensino superior contribui para a formação, consolidação e disseminação, pois o ensino envolve a construção da pesquisa, a comunicação da sociedade influindo a realidade social. Compreendendo esse aspecto, salientamos que, neste estudo, temos como hipótese de trabalho de que a prática docente e a teoria não podem caminhar separadas. Ao contrário disso, elas devem trabalhar conjuntamente e, por isso mesmo, ser inseridas no currículo do ensino superior, seja na graduação, seja na pós-graduação. Para sustentar essa hipótese, vamos neste artigo fazer uma revisão bibliográfica de diversos autores. 
Nos tópicos seguintes, vamos abordar o tema do ensino superior no contexto brasileiro, a partir de uma revisão bibliográfica de diversos autores especialistas no tema. Ressalta-se que não é um estudo exaustivo, mas de caráter bibliográfico que possui, como critério de seleção das obras consultadas, a pertinência para o desenvolvimento do tema aplicado ao contexto brasileiro. Observados esses aspectos teórico-metodológicos desta pesquisa, avancemos para o próximo tópico em que problematizaremos a atividade docente e sua (trans) formação no contexto educacional do ensino superior brasileiro.

\section{Problematizando a prática docente no cenário brasileiro}

A atividade docente no ensino superior tem maior frequência e consistência a partir do século XX, apesar de que a sua ocorrência venha se consolidando desde o século XVI. Corrêa e Ribeiro (2013), a partir dos estudos de Isaia (2006), mostram que há ausência de compreensão por parte de professores e de instituições sobre a preparação específica para exercer a docência no ensino superior, principalmente em seus primórdios. Isso demonstra a relevância de se realizar estudos nessa temática.

Corrêa e Ribeiro (2013) ressaltam ainda que pesquisadores eficientes na área da educação devem ter formação específica em sua área de atuação docente. Por exemplo, é visível o despreparo do professor da área biologia, lecionando matemática. Dessa forma este estudo questiona: A prática docente se relaciona com a teoria crítica? Tendo como objetivo geral: analisar o conceito de prática docente em paralelo com o de teoria crítica aplicada ao Ensino Superior Brasileiro.

Libano (2011) e Anastasiou (2008) justificam que o conhecimento do docente tem como base a sensibilidade da experiência e a indagação teórica. Logo, a formação dos professores demanda investimentos acadêmicos para que os docentes possam estabelecer a relação com o campo e o contexto de produção dos conhecimentos na história e na sociedade (CORRÊA; RIBEIRO 2013) 
Le Boterf (2003) compreende, por sua vez, que a competência é um conceito em construção. Já estudiosos como Dutra, Hipólito e Silva (1998) e Fleury (2001) afirmam que competência não seria apenas um conjunto de qualificações, mas a capacidade de alcançar resultados de acordo com os objetivos propostos. Destarte, é preciso que o professor universitário tenha as competências necessárias para exercer a profissão, independentemente de sua área do conhecimento.

Demo (1998) expõe, ainda, que a competência do educador deve incluir sempre a percepção emancipatória do sujeito. Nesse sentido, deve-se criar oportunidades de ensino-aprendizagem. Para tanto, o questionamento sistemático da realidade é a primeira e principal etapa nesse processo.

Esse questionamento torna-se um componente necessário à teoria e também à prática docente, porque ele auxilia na formação da consciência dos sujeitos a partir do envolvimento do conjunto de posicionamentos e complexidades dos envolvidos. Essa etapa agrega, assim, a ética e os valores dos participantes do processo de ensino e aprendizagem. Portanto, a competência e a crítica à realidade são um desafio para os educadores e para os pesquisadores, de forma geral.

O papel dos docentes, como intelectuais profissionais, é o de direcionar a construção (pesquisa), a (trans)formação (ensino) e a difusão (extensão) do conhecimento científico. Logo, seu papel social não está restrito ao campo da Educação, mas se relaciona com a Cultura, a História e a Política. Pimenta (2003 p. 273) endossa essa postura, porque concebe que a identidade do professor se constrói pelo "diálogo entre a experiência e a história, entre uma experiência e outra e o confronto das práticas com a teoria, num movimento de desvelar, pela análise da prática, a teoria em ação e o processo de investigação da prática".

Compreendemos, desse modo, que a imagem do docente é um conjunto de significados pelos quais os professores são conhecidos. É por meio desse ideal de professor que as pessoas se lembram 
e se relacionam com esse profissional em suas atividades, seja as de docência, seja as de pesquisa e extensão. Além disso, ressalta-se que a coletividade dos professores universitários não tem uma única imagem, e sim várias. Isso ocorre porque existem distintas e diversas crenças, valores e sentimentos relacionadas a essa profissão.

Compreendido esse panorama teórico sobre a imagem do professorado em correlação com sua prática docente, no tópico seguinte, vamos discutir os resultados dessa revisão bibliográfica à luz da teoria crítica. Novamente, salientamos que este não é uma pesquisa exaustiva sobre o tema do ensino superior. $\mathrm{O}$ intuito desta investigação bibliográfica é elucidar alguns pontos de melhoria nas práticas docentes do ensino superior brasileiro, tendo, como hipótese, que a prática docente não pode se sustentar sem a teoria e vice-versa.

\section{Resultados e discussões}

A teoria crítica é um caminho pertinente a ser percorrido por aqueles que estão inseridos enquanto educadores de modo geral. A pesquisa cientifica corrobora a elaboração e apoio dos projetos de pesquisa, uma vez que ela oferece uma metodologia e uma epistemologia. E entre as diversas e diferentes áreas de atuação do ensino superior, o turismo é um campo que precisa ser explorado, haja vista as suas recentes e crescentes demandas. $\mathrm{O}$ estudo do turismo dessa forma é importante para diminuir as iniquidades humanas e não para aumentá-las - este deveria ser o papel das pesquisas científicas e dos pesquisadores comprometidos dentro desse campo.

Diante dessa conjuntura, torna-se imprescindível conhecer melhor a prática docente em suas especificidades. No campo da educação, o modo de atuar na sala de aula é muito heterogêneo, geralmente dependente da postura pessoal do docente e institucional de cada organização. Logo, deve-se perscrutar como o professor planeja, avalia e utiliza as tecnologias e as teorias em suas respectivas aulas no ensino superior de turismo.

Essa investigação é pertinente, porque existem diferentes correntes teóricas e frentes de trabalho na educação, umas volta- 
das para o empreendedorismo inserido no mercado de capitais; já outras, para as teorias implantadas e desenvolvidas no meio acadêmico. Essa diversidade de concepções leva, muitas vezes, a paradoxos no exercício da profissão e da própria docência universitária, conforme já discutem desde a década de 1980 os seguintes autores Beni Trigo (2002), Dencker (2002) e a Ansarah (2002).

Como exemplo dessa formação plural e diversificada, trazemos à luz um estudo de caso, realizado por Catramby e Costa (2005), no Rio de Janeiro que analisou a formação do docente em turismo. O objetivo dessa pesquisa era analisar a qualidade da capacitação dos profissionais formados na área. Os resultados comprovaram a hipótese de que a capacitação docente é um dos fatores que influenciam na qualidade da formação profissional.

O corpo docente analisado nessa pesquisa de Catramby e Costa (2005) constituiu um dos mais relevantes componentes do processo de ensino-aprendizagem, com o projeto pedagógico, a estrutura tecnológica e física das instituições estudadas. Analisou-se, dentro desse componente, a elaboração de currículos, a contratação de professores, os incentivos à capacitação docente e atualização. Esses dados demonstraram que a qualidade do ensino-aprendizagem está relacionada à capacitação e qualidade do corpo docente. Isso ratifica a necessidade de dar prioridade para a formação do corpo docente nas IES.

Outro estudo sobre a prática docente foi A pesquisa de Vicente e Michelin (2012) destacou a importância da qualificação e atualização da formação dos docentes para haver uma melhoramento do ensino didático-pedagógico na área do turismo. Os alunos que geralmente procuram mestrado ou doutorado em turismo são formados em áreas multidisciplinares e, muitas vezes, não se tem formação em cursos de licenciatura. Isso evidencia que muitos alunos e, posteriormente, professores não tiveram contato com a área de pedagogia.

Considera-se fundamental para qualquer educador, não se limitando apenas aos docentes universitários, o conhecimento de 
princípios básicos de pedagogia. Muitos professores entram em sala sem conhecer métodos pedagógicos, técnicas educacionais, princípios de didática, psicologia educacional, assim como novas tendências na área, embora todo curso de licenciatura registrado pelo MEC tenha como obrigatoriedade uma carga horária mínima para esses conteúdos pedagógicos. Todavia, como já enfatizamos, essa obrigatoriedade não consegue abranger à docência em alguns campos da área da educação, principalmente, porque muitos de seus professores não possuem o diploma de licenciatura, mas sim o de bacharel e os de pós-graduação stricto e lato sensu.

Diante desse panorama, percebe-se a necessidade de haver uma formação pedagógica na área lecionada, seja como disciplina, seja como habilitação. Havendo essa lacuna na formação do profissional em educação, o caso da pós-graduação é decorrente dessa conjuntura, pois atualmente quase nenhum programa prepara seus alunos para a prática docente. Em geral, os programas brasileiros incentivam, quase que exaustivamente, à pesquisa. Logo, a preparação pedagógica é esquecida nos currículo de formação dos pós-graduandos.

Esse contexto somente se perpetua porque a formação pedagógica para atuar na docência universitária em educação é pouco exigida ou negligenciada pelos gestores e pela própria comunidade acadêmica da área. A formação para o exercício do ensino na pósgraduação pode ser vista como um campo em que devemos melhorar em termos de pesquisas e práticas. Isso decorre tanto desse contexto já ressaltado, quanto das práticas incrustadas no fazer do professorado e das instituições.

Entende-se por prática pedagógica uma prática social orientada por objetivos, finalidades e conhecimentos, inseridos no contexto de ensino e aprendizagem, conforme Veigas (1989). Esse estudioso explica, ainda, que esse conceito pressupõe a relação direta com a teoria, isto é, no universo da educação, não existe prática sem teoria, nem teoria sem prática. Por conseguinte, o educador deve buscar as condições necessárias para realizar esse 
intercâmbio entre a teoria e a prática, uma vez que ambas são inerentes no dia a dia da sala de aula.

Vasquez (1977), em acordo com esse posicionamento, ressalta que só artificialmente é possível, a partir de um processo de abstração, separar ou isolar teoria da prática. A prática pedagógica, logo, é possível de ser teorizada, do mesmo modo que a teoria precisa ser aplicada. Nessa via de mão dupla, quando notamos que não há condições de formulação de conteúdos pedagógicos na formação do turismólogo, isso acarreta dissonâncias pedagógicas em toda a cadeia produtiva do turismo.

Apoiados em Veigas (1989) e Vasquez (1977), entendemos que o objetivo da prática pedagógica é constituído pelo conjunto de meios, pelo quais as teorias pedagógicas são colocadas em ação pelo professor. O que a distingue da teoria é o caráter real, objetivo, da matéria-prima sobre a qual ela atua nos meios em que exerce a ação. Sua finalidade é, assim, a transformação social das necessidades humanas - eis por que é pertinente ressaltar sua ausência na formação do turismólogo e procurar meios de inseri-la.

Os outros dilemas dessa relação teoria e prática são explorados pelo Centro de Criação e Desenvolvimento Dialógico (CCDD), o qual endossa que o trabalho docente se faz na interface entre o desenvolvimento da prática (conhecimento tácito) e o aprofundamento teórico. Por isso, é equivocada a posição, muito difundida na atualidade, de que a prática basta ao bom professor. $\mathrm{O}$ aprofundamento teórico é essencial para uma ação reflexiva, de qualidade superior, e é preciso cuidado para não cair em qualquer dos extremos: o praticismo e o teoricismo.

A Didática é uma disciplina teórico-prática que pretende subsidiar o professor "em todos os elementos constitutivos da dinâmica escolar, quais sejam: a reflexão pedagógica necessária à implementação de um projeto educativo, com suas concepções explicitadas através de seus planejamentos e efetivadas através de sua dinâmica cotidiana" (MELO; URBANETZ, 2008, p. 32).Como exemplo o governo já propôs o O Programa de Aperfeiçoamento 
de ensino (PAE) que é legalizado em todo o país, mas é uma proposta recente e que carece de maior vigilância e investimento.

Vale destacar ainda que, em acordo com a postura do CCDD, reduzir a formação do professor apenas à prática é negligenciar a possibilidade de ser um intelectual da educação e colocá-lo no papel de executor de atividades pensadas e programadas por sistemas de ensino, leis, autores, dentre outras. Um fator que contribui para esse reducionismo é o engessamento do conteúdo programático das disciplinas.

Para ser um bom docente, não basta apenas ter conhecimento no conteúdo ministrado, mas também entender como disseminar o conhecimento de maneira satisfatória perante os diferentes e diversos tipos de alunado. Cunha (2006) aponta algumas das posturas professorais que podem auxiliar nesse processo de ensino-aprendizagem, a saber: a) explicitar para os alunos o objetivo do estudo que vão realizar; b) localizar historicamente o conteúdo a ser trabalhados; c) incentivar a participação dos alunos via formulação de perguntas; d) usar palavras positivas frente as respostas dos alunos; e) apresentar clareza nas explicações e f) mostrar seriedade e compromisso com a tarefa profissional, dentre outras. Isso demonstra que ações educativas quando bem didatizadas podem transformar o processo de ensino e aprendizagem, melhorando sua eficiência, aderência e produtividade.

\section{Considerações finais}

A ampla implementação do ensino da didática pedagógica como disciplina obrigatória nos programas de pós-graduação em educação pode ser um dos fatores contributivos para a melhoria na formação das IES. Considerando que ainda há grande carência dessa formação pedagógica, salienta-se a dificuldade da inserção do profissionais no mercado de trabalho na área da docência, uma vez que a maioria dos processos seletivos das IES exige prova prática, na qual são requeridos conhecimentos pedagógicos aplicados. Diante dessa situação, não raras vezes, os especialistas de outras áreas encontram-se despreparados. 
Considerando todos esses fatores que envolvem a teoria e a prática, compreendemos, primeiro, que há uma necessidade intrínseca a própria formação do educador e de suas relações de trabalho que reclamam a inserção de disciplinas obrigatórias de didático-pedagogia em seus currículos, seja em sua graduação, seja em sua pós-graduação. Em segundo lugar, nota-se que essa demanda é ainda mais prioritária nos programas de pós-graduação, uma vez que, para além da pesquisa, são eles que formam os futuros docentes das IES.

Por conseguinte, ratificamos, mais uma vez, a importância do ensino pedagógico na formação do docente, bem como o estágio em docência aos pós-graduandos. Sugerimos, apoiados em Vicente e Michelin (2012), que esse estágio possa ser considerado como obrigatório, salvo as exceções para quem já atua na área, pois o estágio deve ser entendido como atividade teórica que permite conhecer e se aproximar da realidade da sala da de aula. Explorado todo esse cenário do ensino superior no Brasil, confirmamos nossa hipótese de que a teoria e a prática docente são intrinsecamente necessárias, pois, a nosso ver, uma convoca e impulsiona a outra.

\section{Referências}

ANASTASIOU, Léa da Graças Camargos. A teoria e a prática de processos de formação continuada do docente universitário. In: ALMEIDA, Maria Isabel de; PIMENTA, Selma Garrido (Orgs.). Pedagogia universitária. São Paulo: EDUSP, 2009. p. 39-70.

ANSARAH, Marilia Gomes Dos Reis. Formação e capacitação do profissional em turismo e hotelaria. Reflexões e cadastro das instituições educacionais no Brasil. São Paulo: Aleph, 2002.

BOTOMÉ. Silvio Paulo. Pesquisa alienada e ensino alienante: o equívoco da extensão universitária. Petrópolis: Vozes; São Carlos: EDUFSCar; Caxias do Sul: EDUCS, 1996.

CORRÊA, Guilherme Torres. RIBEIRO. Victoria. Maria Brant. A formação pedagógica no ensino superior e o papel da pós-graduação stricto sensu. São Paulo: Atlas, 2013. 
CUNHA, Maria Isabel. Docência na Universidade, Cultura e Avaliação Institucional: Saberes Silenciados em Questão. Revista Brasileira de Educação. 2006

DENCKER, Ada. Freitas. Pesquisa e Interdisciplinaridade no Ensino Superior: Uma experiência no curso de turismo. São Paulo: Aleph, 2002.

DEMO, Pedro. Educação \& Conhecimento - Relação necessária, insuficiente e controversa. 2 ed. Petrópolis: Vozes, 2001.

DUTRA, João Silva, Hipólito; SILVA João Martins; MARCONDES, Carlos. Gestão de pessoas por competências. Anais do Encontro Nacional da Associação Nacional de Pós-Graduação e Pesquisa em Administração, Foz do Iguaçu, PR, Brasil, p. 5-17, 1998.

Fleury, Marcos Teles Lima. Estratégias empresariais e formação de competências. São Paulo: Atlas, 2001.

ISAIA, Sérgio Martins Alvarenga. Desafios à docência superior: pressupostos a considerar. In: RISTOFF, Dilvo; SEVEGNANI, Palmira (Orgs.). Docência na educação superior. Brasília: Inep, 2006, p. 15-30.

LE BOTERF, Gerf. De la compétence - essai sur un attracteur étrange. Paris: Quatrième Tirage, 1995.

LIMA, Maria do Socorro de. Imagem e identidade: estudo sobre o professor universitário. 387f. 2012. Tese (Doutorado em Educação) - Programa de PósGraduação em Educação, conhecimento e inclusão social, Universidade de Aveiro, Aveiro/Portugual, 2012.

LIBÂNEO, José Carlos. Conteúdos, formação de competências cognitivas e ensino com pesquisa. In: PIMENTA, Selma Garrido; ALMEIDA, Maria Isabel de (Orgs.). Pedagogia universitária: caminhos para a formação de professores. São Paulo: Cortez. 2011, p. 188-212.

MELO, Alessandro de; URBANETZ, Sandra Terezinha. Fundamentos da didática. Curitiba: Ibpex, 2008.

PIMENTA, Selma Garrido. A pesquisa em Didática (1996 - 1999). In: ANASTASIOU, Léa da Graças Camargos (Org.). Didática, currículo e saberes escolares. Rio de janeiro. DP\&A Editora. 2000, p. 5-21.

TRIGO, Luiz Gonzaga Godoi. A importância da educação para o turismo. In: LAGE, Beatriz Helena Gelas; MILONE, Paulo Cesar (Orgs.). Turismo: teoria e prática. São Paulo: Atlas, 2000, p. 10-25. 
VASQUEZ. Adolfo Sanchez. Filosofia da Práxis. Rio de Janeiro: Paz e Terra, p.241, 1977.

VEIGA, Ilma Passos A. A prática pedagógica do professor de didática. Campinas: Papirus, 1989.

VICENTE, Tâmisa Ramos; MICHELIN, Rita Lourdes. Formação didática na Pós-

Graduação em Turismo no Brasil: evolução, articulações didáticas e desafios para turismólogos docentes Rev. Humanidades, Fortaleza, v. 31, n. 1, p. 42-65, jan./ jun. 2016.

\section{JULIANA FERREIRA DOS SANTOS}

Mestranda do Programa de Pós-Graduação em Turismo

Universidade de São Paulo

Contato: jubahia@usp.br.

\section{MARCOS ROGÉRIO MARTINS COSTA}

Doutorando do Programa de Pós-Graduação em Semiótica e Linguística Geral Universidade de São Paulo

Contato: marcosrmcosta15@gmail.com

\section{PATRÍCIA MARGARIDA FARIAS COELHO}

Professora Doutora do Programa de Pós-Graduação em Educação

Universidade Metodista de São Paulo

Contato: patriciafariascoelho@gmail.com

Enviado: 28/07/2017.

Aprovado: 15/10/2017. 